\title{
Antibody reactivity in patients with IgE-mediated wheat allergy to various subunits and fractions of gluten and non-gluten proteins from $\omega$-gliadin-free wheat genotypes
}

\author{
Andrzej Skoczowski', Krystyna Obtułowicz², Ewa Czarnobilska², Wojciech Dyga², Marcel Mazur², \\ Iwona Stawoska', Jacek Waga ${ }^{3}$ \\ ${ }^{1}$ Institute of Biology, Pedagogical University of Cracow, Kraków, Poland \\ 2 Department of Clinical and Environmental Allergology, Collegium Medicum, Jagiellonian University, Kraków, Poland \\ 3 Plant Breeding and Acclimatization Institute - National Research Institute, Radzików, Poland
}

Skoczowski A, Obtułowicz K, Czarnobilska E, Dyga W, Mazur M, Stawoska I, Waga J. Antibody reactivity in patients with lgE-mediated wheat allergy to various subunits and fractions of gluten and non-gluten proteins from $\omega$-gliadin-free wheat genotypes. Ann Agric Environ Med. 2017; 24(2): 229-236. doi: 10.5604/12321966.1233572

\begin{abstract}
Introduction and objective. Gluten proteins (gliadins and glutenins) are polymorphic wheat storage proteins of allergenic properties. Significant differences in chemical composition between both protein groups allow to expect highly specific immunological response of individual subunits and fractions in reactions with IgE sera of people allergic to wheat. The aim of these studies was to identify and characterize the most allergenic gluten proteins (GP) and nongluten proteins (NGP) occurred in two closely related wheat hybrid genotypes.

Materials and method. $3 x \mathrm{C}$ and $3 \mathrm{xN}$ wheat hybrids, which differ strongly in regard of gliadin composition, were analyzed. Seven people manifesting different symptoms of wheat allergy donated sera for the experiment. The technique of immunoblotting after SDS-PAGE was used for identification of allergenic subunits and fractions among GP and NGP. Immunologically active protein bands were visualized by chemiluminescence.

Results. Great variation of immunodetection spectra was observed. Results of immunoblotting showed LMW glutenins to be of highest, gliadins of medium, while NGP of lowest allergenicity for selected patients. The 43-kDa and 47-kDa LMW glutenin subunits, 40-kDa and 43-kDa $\gamma$-gliadin fractions and 49-kDa NGP can be considered as the most immunoreactive among all protein bands separated by SDS-PAGE.

Conclusion. The observed differentiation of immunodetection spectra allows to model highly specific lgE-binding profiles of allergenic wheat proteins attributed to individual patients with symptoms of gluten intolerance. Highly immunoreactive subunits and fractions among GP and NGP were identified. The observed immunoreactivity of 49 kDa NGP is worth to emphasize, as it has never been reported as wheat allergenic protein before.
\end{abstract}

Key words

gliadins, glutenins, immunoblotting, food allergy, wheat

\section{INTRODUCTION}

In medical sciences gluten is considered as proteinaceous substance of toxic and allergenic properties that is able to trigger celiac and food allergies in people sensitized to wheat proteins. Gluten is composed of hundreds of polymorphic proteins expressed in the endosperm of wheat kernels as storage proteins $[1,2]$. More than $80 \%$ of these proteins belong to gliadins and glutenins, defined as gluten proteins (GP) $[3,4]$. Gliadins and glutenins of individual wheat genotypes may be separated into dozens of protein bands using onedimensional electrophoretic techniques (A-PAGE or SDSPAGE), whereas hundreds of spots may be developed using 2D electrophoresis (IEF/SDS-PAGE) [5, 6]. Traditionally, gliadins are divided into $\alpha, \beta, \gamma, \omega-5$ and $\omega-1.2$ subclasses based on decreased electrophoretic mobility in A-PAGE conditions. In turn, glutenins are composed of high molecular weight

Address for correspondence: Iwona Stawoska, Institute of Biology, Pedagogical University of Cracow, Podchorążych 2, 30-084 Kraków, Poland

E-mail: stawoska@up.krakow.pl

Received: 8 October 2015; accepted: 20 September 2016; first published on February 2017
(HMW) and low molecular weight (LMW) subunits based on SDS-PAGE separations [7].

Glutenins are polymeric proteins. The $\mathrm{C}$ - and N-terminal sequences in glutenin polypeptides contain from one to five cysteine residues that bind individual subunits via intermolecular disulphide bonds (SS), forming large polymeric complexes [8]. Gliadins belonging to $\alpha, \beta$ and $\gamma$ groups also contain cysteines capable of forming SS bonds, however, these disulphides are frequently of intramolecular nature. In consequence, gliadins usually occur as monomeric proteins [9]. Gliadins and glutenins differ also with respect to the number, amino acid composition and localization of short repetitive sequences within polypeptides. The most typical motives are: PQPQPFP and PQQPY in $\alpha$-gliadins, QQQPP in $\gamma$-gliadins and LMW glutenins, PQQPFPQQ in $\omega$-gliadins and PGQGQQ in HMW glutenins [8, 10-12].

Disulphide bonds and repetitive sequences are possibly the most important details influencing immunoreactive properties of GP. SS bonds determine the spatial conformation of the proteins while repetitive sequences may act as $\operatorname{IgE}$ binding epitopes (like QQQPP pentapeptide) $[8,9,11,13,14]$. In consequence, some epitopes can be hidden in the interior, 
while the others exposed on the outer surface of the protein molecules. This may facilitate or aggravate interactions with hyper-variable regions of sIgE antibodies in sera of allergic people, affecting immunoreactive properties of proteins [15].

A range of allergic diseases caused by GP have been diagnosed in the last three decades. One of the important findings in allergology was to prove that $\omega-5$ gliadins are the main allergens involved in wheat-dependent exerciseinduced anaphylaxis (WDEIA) - the most dangerous, life threating form of wheat allergy [16-18]. Omega-5 gliadins may also trigger other wheat allergies, described as exerciseinduced wheat allergy (EIWA) [18]. In turn, $\omega-1.2$ gliadins were evidenced to be allergenic for patients with atopic dermatitis [19]. LMW glutenins play an important role in the development of immediate hypersensitivity to hydrolyzed wheat proteins (IHHWPs) baker's asthma, atopic dermatitis and EIWA $[18,20]$. Battais et al. showed elevated levels of IgE antibodies against all GP in the sera of 28 patients with atopic dermatitis, asthma, urticaria and eczema, which suggested that these proteins were important factors contributing to disease development $[21,22]$.

Another important, proteinaceous components of wheat kernels are nongluten proteins (NGP). Most of them belong to water/salt soluble albumin and globulin groups. The most allergenic NGP are members of the $\alpha$-amylase/ trypsin inhibitors family. In cereals they usually occur as tetrameric or dimeric protein molecules. Low molecular weight subunits (about $12 \mathrm{kDa}$ ) of these proteins - CM2, CM3 and CM16 - known to be major allergens in baker's asthma, have been extensively investigated [23, 24]. Salt soluble NGP of higher molecular weight $(20 \mathrm{kDa}-60 \mathrm{kDa})$ were the objects of this study.

The high polymorphism of gliadins and glutenins, the complex nature of albumins and globulins and a variety of disease symptoms in wheat allergies allow to expect a highly specific immunological response to GP and NGP. One can hypothesize that this specificity may occur not only at the level of protein classes or subclasses, but also at the level of individual subunits and fractions. It would be important to demonstrate which of them are highly allergenic, which are of low allergenicity, or not allergenic at all. Previously we have developed and analyzed hypoallergenic wheat genotypes lacking all $\omega$-gliadins $(3 \mathrm{xN})$, and control genotypes containing all $\omega$-gliadin fractions $(3 \mathrm{xC})[25]$. In the present study we used these genotypes as a model system to investigate immunoreactivity of individual subunits and fractions of GP and NGP.

\section{OBJECTIVES}

The general purpose of this work was to find out whether wheat kernel proteins - comprising both gluten and nongluten proteins - of predicted combination of subunits and fractions, may sensitize wheat allergic persons in distinct manners, causing various symptoms of wheat allergies.

\section{MATERIALS AND METHOD}

Plant material. $3 \mathrm{xC}$ and $3 \mathrm{xN}$ winter wheat hybrid genotypes were analyzed. Both wheats were developed using traditional plant breeding methods based on cross combinations and selection of desirable individuals. Each of parental forms used for crossing donated single null alleles (inactive gene variants) in $\omega$-gliadin coding loci (Gli A1, Gli B1 and Gli D1) localized on chromosomes $1 \mathrm{~A}, 1 \mathrm{~B}$ and $1 \mathrm{D}$. As result of genetical recombinations the $3 \mathrm{xN}$ wheat containing all three null alleles and devoid of all $\omega$-gliadins was developed. In contrast, the $3 \mathrm{xC}$ control line contained the full set of $\omega$-gliadins. In $3 \mathrm{xN}$ considerable decreasing of gliadin allergenic properties and improving of wheat technological properties as compared to $3 \mathrm{xC}$ was demonstrated. A complete characteristics of wheat kernel proteins' composition by A-PAGE, SDS-PAGE and RP-HPLC, technological properties and gliadins' immunoreactivity in $3 \mathrm{xC}$ and $3 \mathrm{xN}$ have been described in one of our previous works [25]. In the present work both wheat genotypes were used as a model system for the research on wheat allergy.

Patients. Seven individuals manifesting different symptoms of wheat allergy and different sIgE levels in response to gluten were selected from among patients treated at the Department of Clinical and Environmental Allergology, Jagiellonian University, Collegium Medicum (Krakow, Poland) (table 1).

Extraction and separation of wheat proteins. Kernel samples from $3 \mathrm{xC}$ and $3 \mathrm{xN}$ wheats (200 g each) were milled using a Quadrumat Junior (Brabender, Germany) laboratory mill. $400 \mu \mathrm{l}$ of $0.15 \mathrm{M} \mathrm{NaCl}$ was added to $40-\mu \mathrm{g}$ flour samples to remove NGP. In order to improve the selectivity of NGP extraction $0.15 \mathrm{M} \mathrm{NaCl}$ (instead $0.5 \mathrm{M} \mathrm{NaCl}$ ) was used. The obtained suspension was centrifuged (1000 rpm, $10 \mathrm{~min}$ ) and supernatants were stored in Eppendorf tubes. Pellets were incubated with $400 \mu \mathrm{l}$ of $70 \% \mathrm{EtOH}$ for two hours to extract gliadins (the obtained gliadins were analyzed in both the reduced and non-reduced state). After centrifugation, supernatants were stored, while the pellets were treated overnight with glutenin extraction buffer composed of $6 \mathrm{M}$ urea, $2.5 \%$ SDS and 1.5\% mercaptoethanol and centrifuged again. The resulting extract contained HMW and LMW glutenins.

Composition of wheat kernel proteins was determined by SDS-PAGE. Proteins were separated in a Mini Protean II Cell using Mini Protean TGX Precast Gels, 10\% Resolving Gel $(8.6 \mathrm{~cm} \times 7.2 \mathrm{~cm})$ in ten-fold diluted Tris/Glycine/ SDS concentrated buffer (BioRad, USA). During each electrophoretic run, four protein extracts: glutenins, native and reduced gliadins and NGP were separated on two gel slabs simultaneously. Electrophoresis was carried out for $50 \mathrm{~min}$ at a constant voltage of $200 \mathrm{~V}$, while the current varied during the run. After electrophoresis, one of the two gel slabs was stained in Comassie Brillant Blue (0.02\% R 250) dye solution to visualize all protein subunits and fractions, while the second one was used for blotting and immunodetection of separated proteins.

Blotting and detection of immunoreactive proteins. Proteins from the gel slabs were transferred to polyvinylidene didifluoride (PVDF) membranes (Immobilon P, Millipore, USA) of $0.45-\mu \mathrm{m}$ thickness, fitted to the dimensions of the gel slab. Blotting was performed using a Transblot SD apparatus (BioRad, USA) in semidry conditions according to Curioni et al. (1991) [26] for 1 hour at $100 \mathrm{~V}$. Detection of immunoreactive protein subunits and fractions was performed according to the procedure described in our 
previous work with several modifications [27]. Membranes after electrotransfer were placed in a blotting container and blocked for 1 hour in 3\% defatted, commercial milk with $1 \%$ bovine serum albumin in PBST solution. PBST was prepared from ready-to-use pills (Sigma, USA) according to the manufacturer's instruction with the addition of $100 \mu$ l of Tween. Immediately after removing the blocking agent, sera of individual patients diluted 1:10 in PBST were added to the container with PVDF membrane and gently shaken overnight. After incubation, membranes were washed five times with PBST for about $40 \mathrm{~min}$ and incubated again with secondary antibodies - anti-human IgE conjugated with HRP (Sigma, USA) diluted 1:1000 in PBST. Immunoreactive proteins were detected by incubation with a chemiluminescence substrate (BioRad, USA) for $5 \mathrm{~min}$ and visualized in a Chemi Doc XRS+ molecular imager (BioRad, USA). Image analysis and calculation of molecular masses were performed using Image Lab Software (BioRad, USA).

\section{RESULTS}

Great differentiation of immunoblotting patterns between individual patients and wheat genotypes was observed. Sera of four persons showed positive reactions with GP (glutenins and reduced gliadins), but not with NGP. Sera of the remaining three subjects recognized both GP and NGP. However, no immunoreaction was observed for non-reduced gliadins.

Three and four immunoreactive bands were identified among $3 \mathrm{xC}$ and $3 \mathrm{xN} \mathrm{GP}$, respectively, probed with the serum of patient 1 (Figure 1). In the $3 \mathrm{xC}$ wheat, one LMW glutenin of $\mathrm{MW}=32 \mathrm{kDa}$ and one HMW glutenin of $\mathrm{MW}=101 \mathrm{kDa}$ (corresponding to Dx2 subunit) were clearly visible. However, in the $3 \mathrm{xN}$ wheat, two LMW glutenins (43 and $36 \mathrm{kDa}$ ) and one HMW glutenin of $101 \mathrm{kDa}$ were detected. In turn, one protein band of $\mathrm{MW}=30 \mathrm{kDa}$ was detected among the reduced gliadins in both $3 \mathrm{xC}$ and $3 \mathrm{xN}$ wheat genotypes.

More immunoreactive proteins were recorded on the immunoblot of patient 2 (Figure 2). Four and five subunits of LMW glutenins in $3 \mathrm{xC}$ and $3 \mathrm{xN}$, respectively, showed clear chemiluminescence signals. Their molecular weights ranged from 32 to $50 \mathrm{kDa}$. Two immunoreactive fractions of reduced gliadins were identified in the $3 \mathrm{xC}$ and $3 \mathrm{xN}$ wheats: a $32-\mathrm{kDa}$ gliadin band was common for both genotypes, while the second one had $36 \mathrm{kDa}$ in $3 \mathrm{xC}$ and 40 $\mathrm{kDa}$ in $3 \mathrm{xN}$.

Although the immunodetection quality for sera 3 and 4 was poorer, several immunoreactive proteins could be identified. LMW subunits of molecular weights: $47 \mathrm{kDa}$, $43 \mathrm{kDa}$ and $40 \mathrm{kDa}$ were detected in both $3 \mathrm{xC}$ and $3 \mathrm{xN}$ lines probed with the serum of patient 3 (Figure 3 ). This triplet in $3 \mathrm{xN}$ was accompanied by one additional $38-\mathrm{kDa}$ band. Among the reduced gliadins, three immunoreactive bands $(43,38$ and $30 \mathrm{kDa})$ were identified in $3 \mathrm{xN}$, however, in $3 \mathrm{xC}$ these were spots rather than clear band that were acquired. This was particularly the case for proteins of molecular weight ranging from 30 to $38 \mathrm{kDa}$. In contrast to other immunoblotting patterns obtained in this study, immunoblots of the $3 \mathrm{xC}$ wheat detected a $60-\mathrm{kDa} \omega-5$ gliadin band both in the reduced and non-reduced extracts.

Serum of patient 4 reacted with a number of glutenin subunits $(30-88 \mathrm{kDa})$ and reduced gliadins $(30-47 \mathrm{kDa})$. A wide spectrum of immunoreactive bands comprised almost all of the $3 \mathrm{xC}$ and $3 \mathrm{xN}$ wheat proteins (Figure 4).

Three patients potentially allergic to GP as well as NGP demonstrated specific patterns of immunoreactivity. Nine and eleven glutenin subunits in the $3 \mathrm{xC}$ and $3 \mathrm{xN}$ wheat lines, respectively, were immunodetected in the sample with the serum of patient 5 (Figure 5). The expressed glutenin bands were well separated and of medium intensity. The LMW subunit of $40 \mathrm{kDa}$ in the $3 \mathrm{xC}$ wheat was the only one showing slightly stronger luminescence signal as compared to other immunoreactive proteins. Reduced gliadins, in turn, were represented as faint blurry spots ranging in molecular weight from 30 to $43 \mathrm{kDa}$. In contrast, a single sharp band of $49 \mathrm{kDa}$ was observed among NGP in both wheats.

Numerous immunoreactive glutenin bands probed with the serum of patient 6 were observed. A single band of $47 \mathrm{kDa}$ showed stronger luminescence as compared to other HMW and LMW subunits in the $3 \mathrm{xC}$ and $3 \mathrm{xN}$ wheats (Figure 6). Among the reduced gliadins, one and two immunoreactive bands were detected in $3 \mathrm{xC}$ and $3 \mathrm{xN}$, respectively. Contrary to patient 5 , these signals were weaker, but the bands were

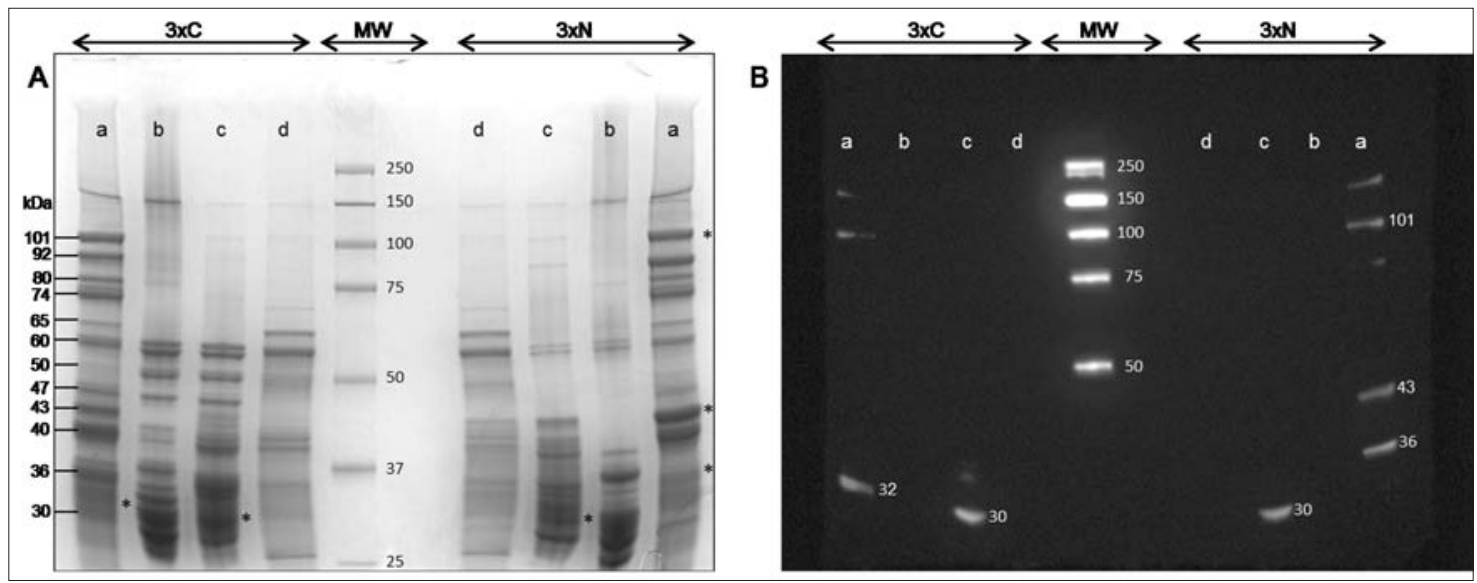

Figure 1. Wheat kernel proteins (glutenins, gliadins and salt soluble proteins) extracted from $3 \times \mathrm{C}$ and $3 \times \mathrm{N}$ wheats, separated by SDS-PAGE (A) and immunobloted with the lgE sera of patient 1 (B). Immunoreactive subunits and fractions are marked by asterix (on the electrophoregam) and by molecular mass values (on the immunoblot) on the right hand sides of each run. Molecular masses of the reference bands for HMW and LMW glutenin subunits are are given on the left hand side of the run „a" ( $\mathrm{a}-\mathrm{HMW}$ and LMW glutenin subunits, $\mathrm{b}$ - non-reduced gliadins, c - gliadins reduced by mercaptoethanol, $\mathrm{d}$ - salt soluble proteins) 


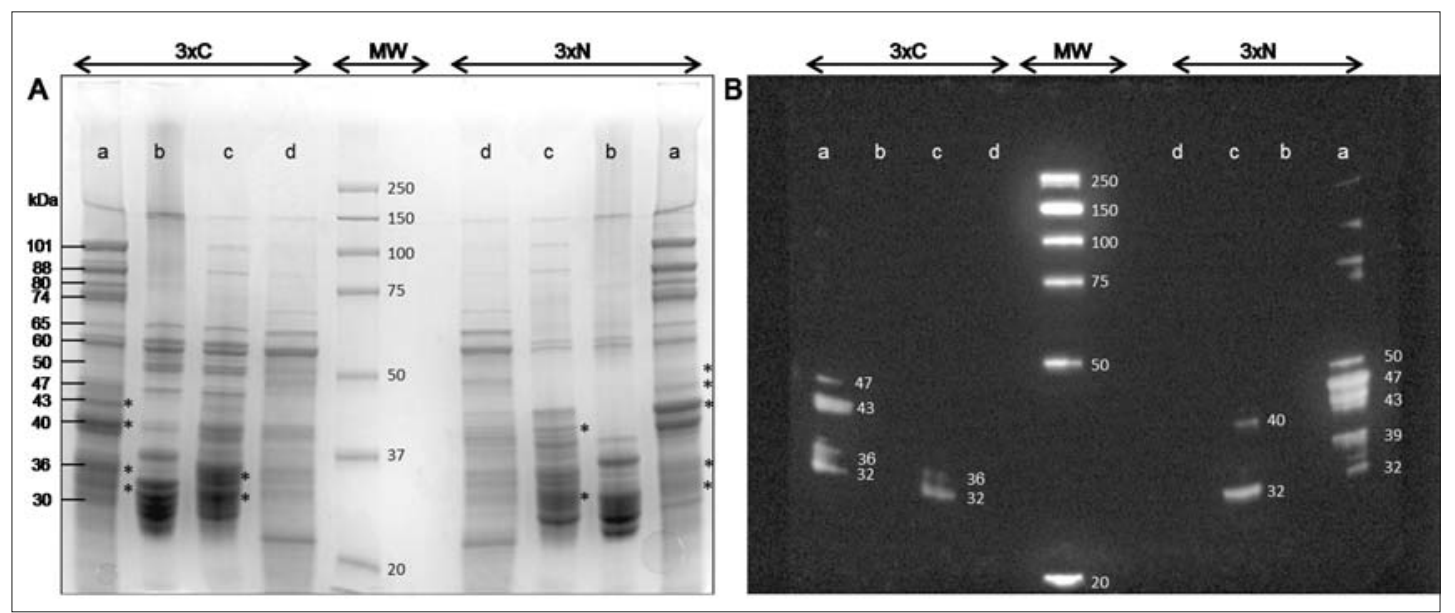

Figure 2. Patient 2. Electrophoretic (A) and immunoblotting (B) data as on Figure 1

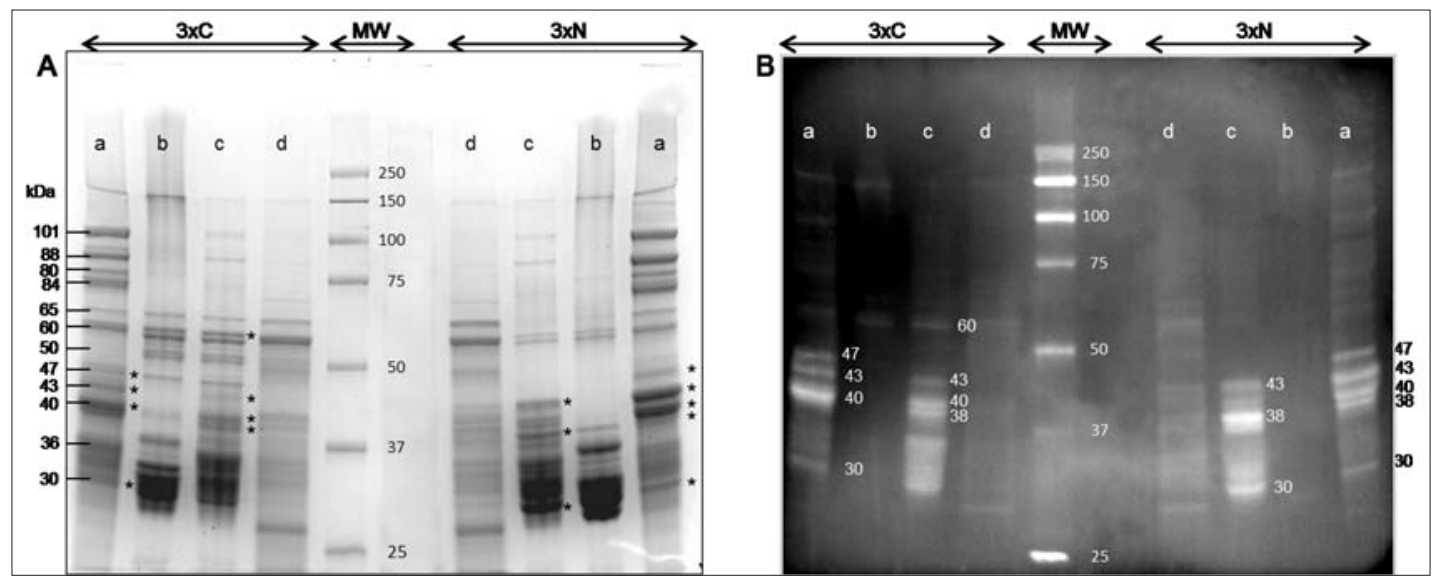

Figure 3. Patient 3. Electrophoretic (A) and immunoblotting (B) data as on Figure 1

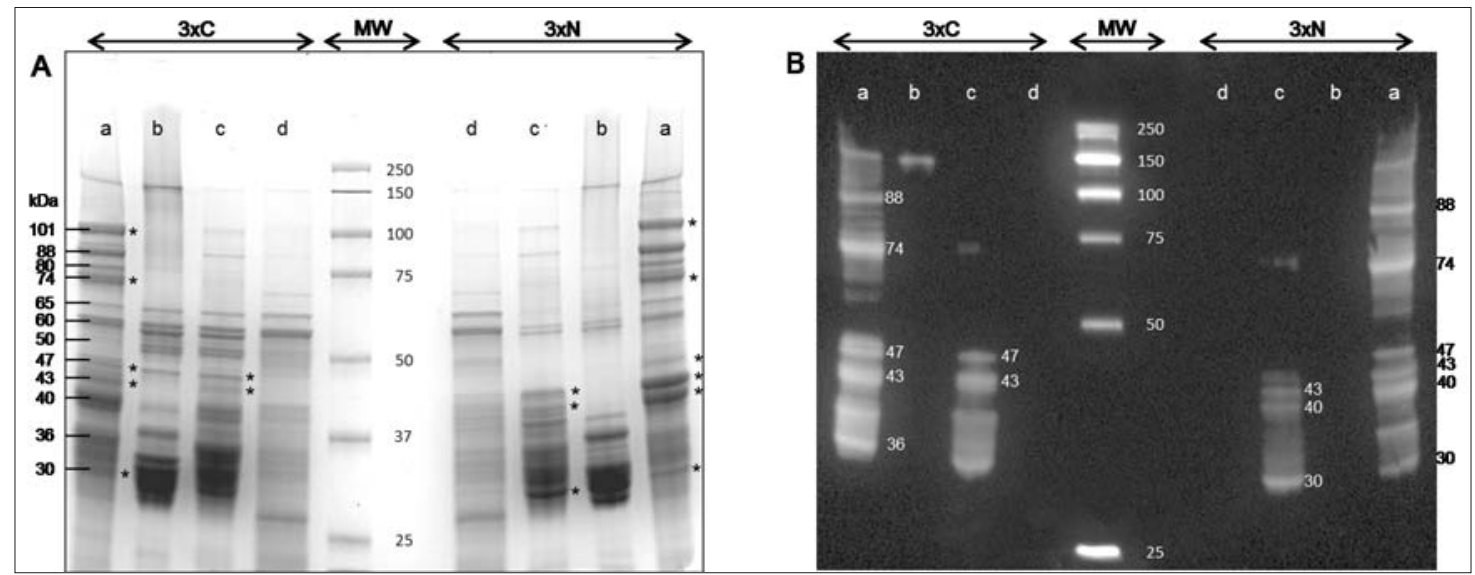

Figure 4. Patient 4. Electrophoretic (A) and immunoblotting (B) data as on Figure 1

clear and sharp. NGP protein extracts gave a single distinct $49-\mathrm{kDa}$ band in both varieties. Moreover, in 3xC this protein was accompanied by an additional $36-\mathrm{kDa}$ band.

The highest number of immunoreactive proteins was observed on the immunoblot of patient 7 in all protein groups (Figure 7). Several LMW subunits could be classified as highly immunoreactive. In the $3 \mathrm{xC}$ variety these were bands of 47 , 43,42 and $40 \mathrm{kDa}$, and $47-\mathrm{kDa}$ and $43-\mathrm{kDa}$ proteins in the $3 \mathrm{xN}$ wheat. It is worth emphasizing that the $43-\mathrm{kDa}$ band in the $3 \mathrm{xN}$ wheat extract had the highest luminescence intensity of all proteins immunodetected in this study. The $43-\mathrm{kDa}$ gliadin band of $3 \mathrm{xN}$ wheat was also clear and markedly distinct from other smeary overlapping and poorly stained fractions. A wide spectrum of immunoreactive NGP bands (ranging from 14 to $65 \mathrm{kDa}$ ) was identified in both $3 \mathrm{xC}$ and $3 \mathrm{xN}$ wheats. However, they were poorly stained and frequently overlapped each other. The only exception was a $43-\mathrm{kDa}$ protein in the extract of $3 \mathrm{xN}$ wheat that was also clearly stood out from other NGP.

Based on the frequency of immunoreactive bands, several GP and NGP can be considered as important allergens for the patients examined. The highest number of detected proteins 


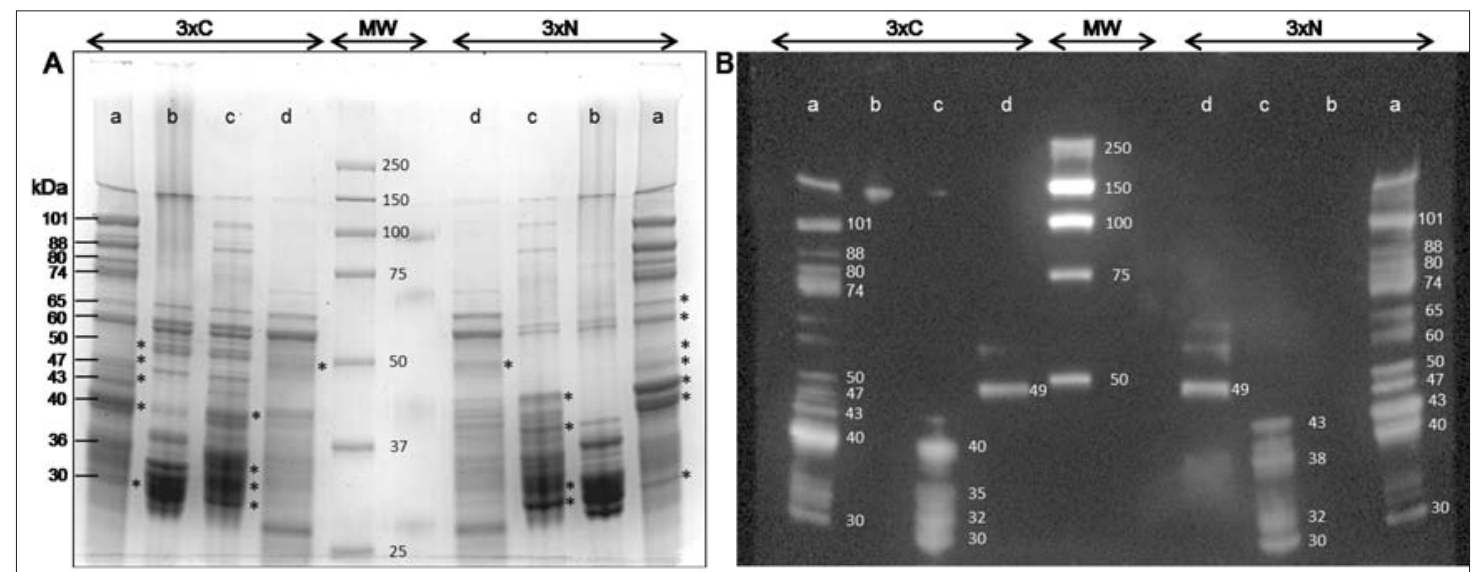

Figure 5. Patient 5. Electrophoretic (A) and immunobloting (B) data as on Figure 1

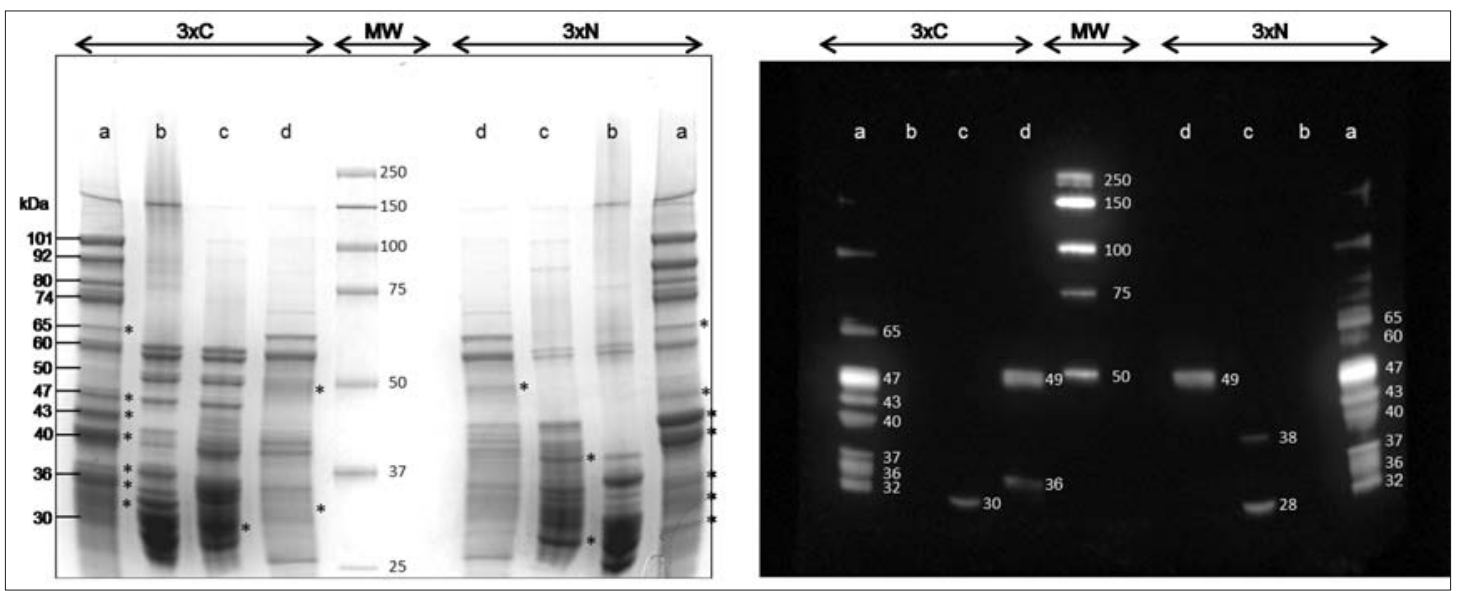

Figure 6. Patient 6. Electrophoretic (A) and immunoblotting (B) data as on Figure 1

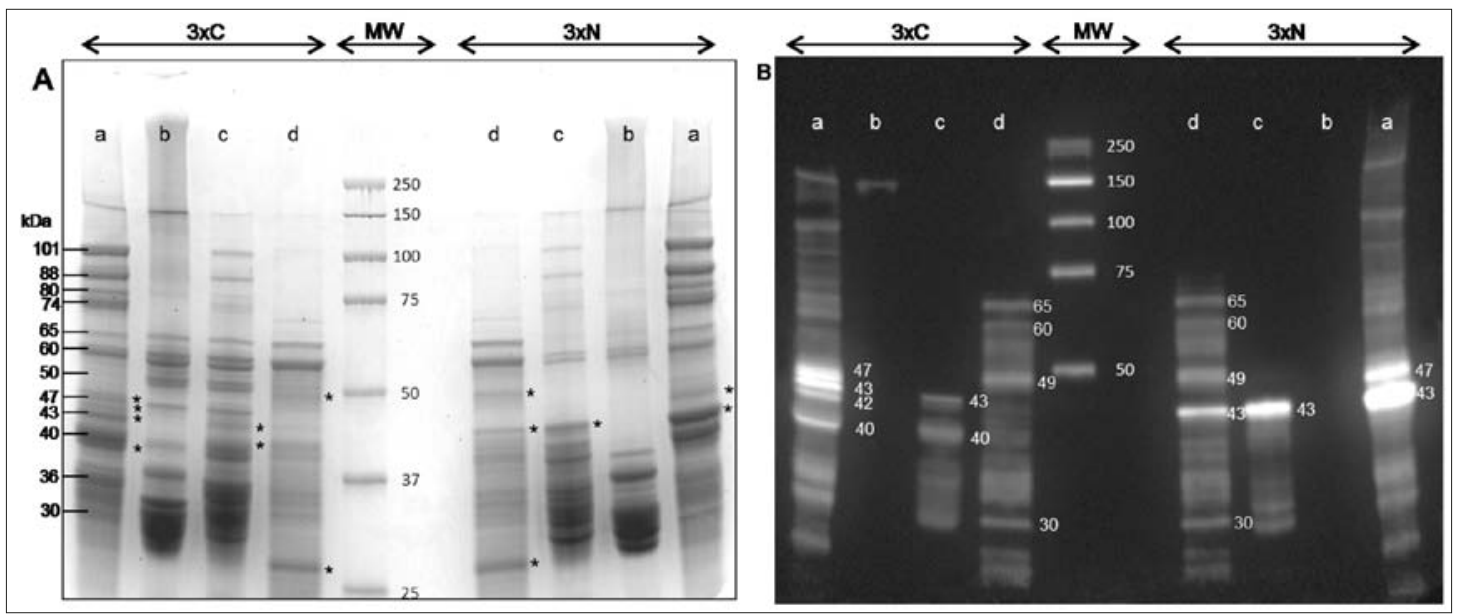

Figure 7. Patient 7. Electrophoretic (A) and immunoblotting (B) data as on Figure 1

was observed among glutenins, especially among the LMW subunits. A total of $13 \mathrm{LMW}$ glutenin bands in $3 \mathrm{xC}$ and 16 in the $3 \mathrm{xN}$ wheat were classified as immunoreactive proteins (Table 1). In the $3 \mathrm{xC}$ wheat, $43-\mathrm{kDa}$ and $47-\mathrm{kDa}$ subunits were detected in almost all patients studied. The remaining $32-\mathrm{kDa}, 36-\mathrm{kDa}$ and $40-\mathrm{kDa}$ subunits were immunoreactive in about half of the subjects included in the experiments. HMW glutenins of molecular weights 74 and $88 \mathrm{kDa}$, corresponding to Dy12 and Bx7 subunits, respectively, were detected in the sera of two patients. Other glutenins showed immunoreactivity with sera of individual patients.
Ten gliadin fractions specific for the $3 \mathrm{xC}$ wheat and five gliadins specific for $3 \mathrm{xN}$ were recognized as immunoreactive in the current study (Table 2). The most frequently immunodetected gliadins of molecular weights 30, 40, and 43 $\mathrm{kDa}$ were recorded in approximately half of the study patients. The remaining fractions, including $47-\mathrm{kDa} \gamma$-gliadin and 60 $\mathrm{kDa} \omega$-gliadin, from the $3 \mathrm{xC}$ variety were immunoreactive in single patients, however, no immunodetection of these bands was observed with $3 \mathrm{xN}$ extracts.

Among six immunodetected NGP, only one fraction of $\mathrm{MW}=49 \mathrm{kDa}$ was recognized by the sera of all three patients 
Table 1. Clinical data of seven wheat-allergic patients

\begin{tabular}{cccll}
\hline $\begin{array}{c}\text { Patient } \\
\text { No. }\end{array}$ & Sex & Age & Profession & Wheat induced symptoms \\
\hline 1 & M & 67 & baker - confectioner & rhinitis, asthma \\
\hline 2 & M & 53 & house keeper & urticaria, angioedema \\
\hline 3 & M & 57 & policeman & $\begin{array}{l}\text { anaphylactic reactions } \\
\text { (urticaria, tongueangioedema and } \\
\text { anaphylactic shock) }\end{array}$ \\
\hline 4 & M & 34 & baker - confectioner & $\begin{array}{l}\text { rhinitis, asthma, allergic contact } \\
\text { dermatitis }\end{array}$ \\
\hline 5 & F & 52 & book-keeper & asthma, rhinitis \\
\hline 6 & M & 36 & baker - confectioner & asthma \\
\hline 7 & M & 44 & desktop publisher & asthma, atopic dermatitis \\
\hline
\end{tabular}

Table 2. Frequency distribution of immunoreactive HMW and LMW glutenin subunits in the analyzed group of wheat-allergic patients

\begin{tabular}{|c|c|c|c|c|c|}
\hline \multirow{2}{*}{$\mathrm{MW}(\mathrm{kDa})$} & \multicolumn{2}{|c|}{$3 \times C$} & \multirow{2}{*}{ MW (kDa) } & \multicolumn{2}{|c|}{$3 \times N$} \\
\hline & NP & \%all & & NP & \%all \\
\hline 43 & 6 & 86 & 43 & 7 & 100 \\
\hline 47 & 6 & 86 & 47 & 6 & 86 \\
\hline 40 & 4 & 57 & 40 & 4 & 57 \\
\hline 32 & 3 & 43 & 50 & 2 & 29 \\
\hline 36 & 3 & 43 & 36 & 2 & 29 \\
\hline 74 & 2 & 29 & 32 & 2 & 29 \\
\hline 88 & 2 & 29 & 30 & 2 & 29 \\
\hline 30 & 1 & 14 & 88 & 2 & 29 \\
\hline 37 & 1 & 14 & 74 & 2 & 29 \\
\hline 50 & 1 & 14 & 65 & 2 & 29 \\
\hline 65 & 1 & 14 & 60 & 2 & 29 \\
\hline 80 & 1 & 14 & 101 & 1 & 14 \\
\hline 101 & 1 & 14 & 39 & 1 & 14 \\
\hline 38 & 0 & 0 & 38 & 1 & 14 \\
\hline 39 & 0 & 0 & 80 & 1 & 14 \\
\hline 60 & 0 & 0 & 37 & 1 & 14 \\
\hline
\end{tabular}

$\mathrm{NP}$ - number of patients sensitized to a protein of predicted molecular weight all - percentage in relation to all patients participating in the experiment

sensitized to NGP (Table 3). The remaining NGP were immunodetected by individual patients.

Table 3. Frequency distribution of immunoreactive reduced gliadin fractions in the analyzed group of wheat-allergic patients

\begin{tabular}{ccccccc}
\hline \multirow{2}{*}{$\begin{array}{c}M W \\
(\mathrm{kDa})\end{array}$} & \multicolumn{3}{c}{$3 \times \mathrm{C}$} & & $\mathrm{MW}$ & \multicolumn{3}{c}{$3 \times \mathrm{N}$} \\
\cline { 2 - 3 } & $\mathrm{NP}$ & \%all & & $(\mathrm{kDa})$ & $\mathrm{NP}$ & \%all \\
\hline 30 & 3 & 43 & 30 & 5 & 71 \\
\hline 40 & 3 & 43 & 43 & 4 & 57 \\
\hline 43 & 3 & 43 & 38 & 3 & 43 \\
\hline 32 & 2 & 29 & 32 & 2 & 29 \\
\hline 28 & 1 & 14 & 40 & 2 & 29 \\
\hline 35 & 1 & 14 & 28 & 0 & 0 \\
\hline 36 & 1 & 14 & 35 & 0 & 0 \\
\hline 38 & 1 & 14 & 36 & 0 & 0 \\
\hline 47 & 1 & 14 & 47 & 0 & 0 \\
\hline 60 & 1 & 14 & 60 & 0 & 0
\end{tabular}

$\mathrm{NP}$ - number of patients sensitized to a protein of predicted molecular weight

all - percentage in relation to all patients participating in the experiment
Table 4. Frequency distribution of immunoreactive salt soluble proteins in the analyzed group of wheat-allergic patients

\begin{tabular}{|c|c|c|c|c|c|c|c|}
\hline \multirow{2}{*}{$\mathrm{MW}(\mathrm{kDa})$} & \multicolumn{3}{|c|}{$3 \times C$} & \multirow{2}{*}{$\begin{array}{c}\mathrm{MW} \\
(\mathrm{kDa})\end{array}$} & \multicolumn{3}{|c|}{$3 \times N$} \\
\hline & NP & \%s.s. & \%all & & NP & \%s.s. & \%all \\
\hline 49 & 3 & 100 & 43 & 49 & 3 & 100 & 43 \\
\hline 30 & 1 & 33 & 14 & 30 & 1 & 33 & 14 \\
\hline 36 & 1 & 33 & 14 & 43 & 1 & 33 & 14 \\
\hline 60 & 1 & 33 & 14 & 60 & 1 & 33 & 14 \\
\hline 65 & 1 & 33 & 14 & 65 & 1 & 33 & 14 \\
\hline 43 & 0 & 0 & 0 & 36 & 0 & 0 & 0 \\
\hline
\end{tabular}

$\mathrm{NP}$ - number of patients sensitized to a protein of predicted molecular weight; s.s. - percentage in relation to patients sensitized to salt soluble proteins; all - percentage in relation to all patients participating in the experiment

\section{DISCUSSION}

In the present study immunoreactive properties of individual subunits and fractions of GP and NGP in two closely related wheat hybrid genotypes $3 \mathrm{xC}$ and $3 \mathrm{xN}$ were analyzed. Immunoblotting technique was used to investigate whether, and to what extent, patterns of immunoreactive proteins were specific for individual wheat allergic patients. The analyzed wheat hybrids were immuno-positive for a number of bands representing $\alpha, \beta, \gamma$ gliadins, LMW glutenins and NGP. These results have confirmed the immunoreactivity of $\alpha, \beta$ and $\gamma$ gliadins, previously reported in our study that tested purified gliadin fractions by ELISA [28]. The current work is also consistent with the results obtained by other authors who reported allergenicity of $\alpha, \beta$ and $\gamma$ gliadins in atopic dermatitis, and LMW glutenins in baker's asthma $[20,29,30]$. The study of Maruyama et al. [31] determined their relative reactivity in the following order: glutenins $>$ gliadins $>$ NGP. However, in the present study, the specificity of the obtained IgE-binding profiles was observed at the level of individual subunits and fractions of GP and NGP, which allowed to consider patterns of IgE binding as fingerprints characteristic for individual patients. This variation confirmed our hypothesis that the immunological response to wheat proteins is highly specific. The identified protein bands showed very strong, very weak or a complete absence of luminescence signal depending on the wheat variety and serum applied. This indicated that the combination of immunoreactive bands was associated with both patient and wheat genotype.

Most of the research on wheat allergenic proteins has thus far concerned $\omega-5$ gliadins. It seems obvious as the $\omega-5$ gliadin fractions act as the main allergens in WDEIA $[18,32-34]$. However, $\omega-5$ can be also active in other wheat allergies [21, 35]. Hence, we could expect the detection of $\omega-5$ by at least some of the sera tested. The study showed that only one patient's (3) IgEs bound $60-\mathrm{kDa} \omega-5$ gliadin derived from the $3 \mathrm{xC}$ wheat, while no immunodetection was observed in $3 \mathrm{xN}$ wheat samples. This finding suggests that patient 3 may be potentially threatened by WDEIA, while consuming food products containing flour from the $3 \mathrm{xC}$ type wheat. This risk, however, may be theoretically eliminated by substituting the latter for the $3 \mathrm{xN}$ wheat of potentially hypoallergenic properties in WDEIA.

Despite the high specificity of the IgE binding profiles, certain immunodetected proteins are likely important allergens, common for all patients examined. Taking into consideration the intensity of chemiluminescence signals and 
the frequency of immunodetection by individual sera, the highest immunoreactivity was observed for 43-kDa and 47kDa LMW glutenin subunits and 40-kDa $\gamma$-gliadin fraction. The observed immunodetection of $49-\mathrm{kDa}$ NGP is especially worth to emphasize as it has never been reported as wheat allergenic protein before. Other studies frequently reported NGP proteins of lower MW $12-14 \mathrm{kDa}$ as highly allergenic proteins $[23,24,36]$. In this study NGP of higher molecular weight (between $20 \mathrm{kDa}$ and $65 \mathrm{kDa}$ ) were analyzed. All three patients, whose IgE sera detected the $49-\mathrm{kDa}$ NGP have been also diagnosed with asthma symptoms, which suggests this protein may also plays an important role in disease development. Identification of the most allergenic components among GP and NGP is necessary for further development of hypoallergenic wheat genotypes lacking harmful proteins, tailored to the specific immunological response of individual patients.

The obtained results showed - to some degree - weakness of the present diagnostic methods that exclusively signalize whether examined patients are gluten sensitized or not. As demonstrated in this paper allergic reaction of individual patients may be different and strongly depends on combination of subunits and fractions of gluten and nongluten proteins. Based on the immunoblots it is possible to elaborate methodology of patient's sensitizing level prediction what probably relates to number and intensity of immunodetected protein bands. Hence, our results make basement for improving diagnostic methods used in allergology.

Comparison of immunoreactivity of native and reduced proteins allow to hypothesize whether conformational or linear epitopes play more important role in the IgE binding $[30,31]$. Our findings evidently demonstrated no $\operatorname{IgE}$ detection of non-reduced gliadins, which indicated that $\alpha$, $\beta$ and $\gamma$ fractions gained immunoreactivity only after the disruption of SS bonds and unfolding of protein molecules. This in turn may suggest an important role of linear epitopes in the IgE binding. Potentially, a more extended structure of the molecule after the reduction of disulphides facilitate recognition of linear epitopes by IgE antibodies.

\section{CONCLUSIONS}

1) Sensitizing properties of wheat are due to particular components among gluten protein and on-gluten proteins, rather than the whole gluten complex.

2) Immunobloting patterns of allergenic wheat kernel proteins are highly specific with regard to both patients and wheat genotypes.

3) The most immunoreactive wheat proteins are the $43 \mathrm{kDa}$ and $47 \mathrm{kDa}$ subunits of the low-molecular weight glutenins, as well as $40 \mathrm{kDa} \gamma$-gliadin fraction and the $49 \mathrm{kDa}$ fraction of non-gluten proteins.

\section{Acknowledgement}

This work was financially supported by the Polish National Center of Science under Grant nr N N312 182938 realized in years 2011-2013.

\section{REFERENCES}

1. Wrigley C, Békés F, Bushuk W. Gluten: A balance of gliadin and glutenin. In: Wrigley C, Békés F, Bushuk W, editors. Gliadin and glutenin. The unique balance of wheat quality. Minnesota, USA; AACC International, St Paul; 2006. p. 3-32.

2. Metakovsky E, Graybosch R. Gliadin alleles in wheat: identification and applications. In: Wrigley C, Békés F, Bushuk W, editors. Gliadin and Glutenin: The Unique Balance of Wheat Quality. Minnesota, USA; AACC International, St Paul; 2006. p. 85-114.

3. Payne PI. Genetics of Wheat Storage Proteins and the Effect of Allelic Variation on Bread-Making Quality. Annu Rev Plant Physiol. 1987; 38(1): 141-153.

4. Sozinov A, Poperelya F. Genetic classification of prolamines and its use for plant breeding. Ann Techn Agric. 1980; 29(2): 229-245.

5. Metakovsky E, Gomez M, Vazquez J, Carrillo J. High genetic diversity of Spanish common wheats as judged from gliadin alleles. Plant Breed. 2000; 119(1): 37-42.

6. Dupont FM, Vensel WH, Tanaka CK, Hurkman WJ, Altenbach SB. Deciphering the complexities of the wheat flour proteome using quantitative two-dimensional electrophoresis, three proteases and tandem mass spectrometry. Proteome Sci. 2011; 9(10): 1-29.

7. Shewry PR, Tatham AS, Halford NG. The prolamins of the Triticeae. In: Shewry PR, Casey R, editors. Seed proteins. Dordrecht; Springer Netherlands; 1999. p. 35-78.

8. Shewry PR, Halford NG, Tatham AS, Popineau Y, Lafiandra D, Belton PS. The high molecular weight subunits of wheat glutenin and their role in determining wheat processing properties. Adv Food Nutr Res. 2003; 45: 219-302.

9. Shewry P, Tatham A. Disulphide bonds in wheat gluten proteins. J Cereal Sci. 1997; 25(3): 207-227.

10. Bonomi F, Iametti S, Mamone G, Ferranti P. The Performing Protein: Beyond Wheat Proteomics? Cereal Chem. 2013; 90(4): 358-366.

11. Tanabe S. Identification of wheat allergens. Internet Symposium Food Allergens. 2001; 3(4): 163-170.

12. Tatham AS. The structures of wheat proteins. In: Schofield JD, Editor. Wheat Structure: Biochemistry and Functionality. Cambridge, UK; The Royal Society of Chemistry; 1996. p. 53-62.

13. Köhler P, Belitz H-D, Wieser H. Disulphide bonds in wheat gluten: further cystine peptides from high molecular weight (HMW) and low molecular weight (LMW) subunits of glutenin and from $\gamma$-gliadins. Zeitschrift für Lebensmittel-Untersuchung und Forschung. 1993; 196(3): 239-247.

14. Tanabe S, Arai S, Yanagihara Y, Mita H, Takahashi K, Watanabe M. A major wheat allergen has a Gln-Gln-Gln-Pro-Pro motif identified as an IgE-binding epitope. Biochem Biophys Res Commun. 1996; 219(2): 290-293.

15. Aalberse RC, Crameri R. IgE-binding epitopes: a reappraisal. Allergy. 2011; 66(10): 1261-1274.

16. Palosuo K, Varjonen E, Kekki O-M, Klemola T, Kalkkinen N, Alenius H, et al. Wheat $\omega-5$ gliadin is a major allergen in children with immediate allergy to ingested wheat. J Allergy Clin Immunol. 2001; 108(4): 634638.

17. Morita E, Yamamura Y, Mihara S, Kameyoshi Y, Yamamoto S. Fooddependent exercise-induced anaphylaxis: a report of two cases and determination of wheat- $\gamma$-gliadin as the presumptive allergen. $\mathrm{Br} \mathrm{J}$ Dermatol. 2000; 143(5): 1059-1063.

18. Jacquenet S, Morisset M, Battais F, Denery-Papini S, Croizier A, Baudouin $\mathrm{E}$, et al. Interest of immunoCAP system to recombinant $\omega-5$ gliadin for the diagnosis of exercise-induced wheat allergy. Int Arch Allergy Immunol. 2009; 149(1): 74-80.

19. Lauriere M, Pecquet C, Boulenc E, Bouchez-Mahiout I, Snegaroff J, Choudat D, et al. Genetic differences in omega-gliadins involved in two different immediate food hypersensitivities to wheat. Allergy. 2007; 62(8): 890-896.

20. Snégaroff J, Branlard G, Bouchez-Mahiout I, Laudet B, Tylichova $\mathrm{M}$, Chardot T, et al. Recombinant proteins and peptides as tools for studying IgE reactivity with low-molecular-weight glutenin subunits in some wheat allergies. J Agric Food Chem. 2007; 55(24): 9837-9845.

21. Battais F, Mothes T, Moneret-Vautrin DA, Pineau F, Kanny G, Popineau $\mathrm{Y}$, et al. Identification of IgE-binding epitopes on gliadins for patients with food allergy to wheat. Allergy. 2005; 60(6): 815-821.

22. Battais F, Pineau F, Popineau Y, Aparicio C, Kanny G, Guerin L, et al. Food allergy to wheat: identification of immunogloglin $\mathrm{E}$ and immunoglobulin G-binding proteins with sequential extracts and purified proteins from wheat flour. Clin Exp Allergy. 2003; 33(7): 962-970. 
23. Kusaba-Nakayama M, Ki M, Iwamoto M, Shibata R, Sato M, Imaizumi $\mathrm{K}$. CM3, one of the wheat $\alpha$-amylase inhibitor subunits, and binding of $\operatorname{IgE}$ in sera from Japanese with atopic dermatitis related to wheat. Food Chem Toxicol. 2000; 38(2): 179-185.

24. Zapatero L, Martinez M, Alonso E, Salcedo G, Sánchez-Monge R, Barber D, et al. Oral wheat flour anaphylaxis related to wheat $\alpha$-amylase inhibitor subunits CM3 and CM16. Allergy. 2003; 58(9): 955-960.

25. Waga J, Skoczowski A. Development and characteristics of $\omega$-gliadinfree wheat genotypes. Euphytica. 2014; 195(1): 105-116.

26. Curioni A, Dal Belin Peruffo A, Pressi G, Pogna N. Immunological distinction between $\mathrm{x}$-type and y-type high molecular weight glutenin subunits. Cereal Chem. 1991; 68(2): 200-204.

27. Skoczowski A, Obtułowicz K, Czarnobilska E, Dyga W, Stachowicz M, Waga J. Patient-dependent differentiation of gluten protein IgEbinding epitopes in wheat allergy. Przegl Lek [Medical Review]. 2012; 70(12): 1043-1047.

28. Waga J, Obtułowicz K, Zientarski J, Czarnobilska E, Skoczowski A. Purified Wheat Gliadin Proteins as Immunoglobulin E Binding Factors in Wheat Mediated Allergies. Am J Plant Sci. 2011; 2(03): 476-483.

29. Varjonen E, Vainio E, Kalimo K. Antigliadin IgE-indicator of wheat allergy in atopic dermatitis. Allergy. 2000; 55(4): 386-391.

30. Klockenbring T, Boese A, Bauer R, Goerlich R. Comparative investigations of wheat and spelt cultivars: IgA, IgE, IgG1 and IgG4 binding characteristics. Food Agric Immunol. 2001; 13(3): 171-181.
31. Maruyama N, Ichise K, Katsube T, Kishimoto T, Kawase Si, Matsumura $\mathrm{Y}$, et al. Identification of major wheat allergens by means of the Escherichia coli expression system. Eur J Biochem. 1998; 255(3): 739-745.

32. Matsuo H, Dahlström J, Tanaka A, Kohno K, Takahashi H, Furumura $M$, et al. Sensitivity and specificity of recombinant $\omega-5$ gliadin-specific IgE measurement for the diagnosis of wheat-dependent exerciseinduced anaphylaxis. Allergy. 2008; 63(2): 233-236.

33. Bouchez-Mahiout I, Snégaroff J, Tylichova M, Pecquet C, Branlard G, Laurière M. Low Molecular Weight Glutenins in Wheat-Dependant, Exercise-Induced Anaphylaxis: Allergenicity and Antigenic Relationships with Omega 5-Gliadins. Int Arch Allergy Immunol. 2010; 153(1): 35-45.

34. Hofmann S, Fischer J, Eriksson C, Bengtsson Gref O, Biedermann T, Jakob T. IgE detection to $\alpha / \beta / \gamma$-gliadin and its clinical relevance in wheat-dependent exercise-induced anaphylaxis. Allergy. 2012; 67(11): 1457-1460.

35. Ito K, Futamura M, Borres MP, Takaoka Y, Dahlstrom J, Sakamoto T, et al. IgE antibodies to $\omega-5$ gliadin associate with immediate symptoms on oral wheat challenge in Japanese children. Allergy. 2008; 63(11): 1536-1542.

36. Sanchez-Monge R, Garcia-Casado G, Armentia A, Salcedo G. Wheat flour peroxidase is a prominent allergen associated with baker's asthma. Clin Exp Allergy. 1997; 27(10): 1130-1137. 